\title{
Microstructural evolution and formation mechanism of bimodal structure of $0.2 \%$ carbon steel subjected to heavy-reduction controlled rolling process
}

Hyung-Won Park ${ }^{\mathrm{a}^{\mathrm{a}}}$, Kei Shimojima $\mathrm{a}^{\mathrm{a}}$, Sumio Sugiyama ${ }^{\mathrm{b}}$, Hisanao Komine ${ }^{\mathrm{b}}$, Jun Yanagimoto $^{\mathrm{b}}$

${ }^{a}$ Graduate School of Engineering, The University of Tokyo, Komaba 4-6-1, Meguro-ku 153-8505, Tokyo, Japan

${ }^{\mathrm{b}}$ Institute of Industrial Science, The University of Tokyo, Komaba 4-6-1, Meguro-ku 153-8505, Tokyo, Japan

*Corresponding author: Phone/Fax: +81-3-5452-6204, E-mail address: wonipark@iis.u-tokyo.ac.jp

\begin{abstract}
A heavy-reduction controlled rolling process with approximately $75 \%$ thickness reduction was carried out to investigate the microstructural evolution including texture development, focusing on the formation of a bimodal structure of $0.2 \%$ carbon steel with heating temperatures of $700,800,900$, and $1000{ }^{\circ} \mathrm{C}$. Upon increasing the heating temperature from 700 to $900{ }^{\circ} \mathrm{C}$, the microstructure was refined and precipitates such as $\mathrm{Fe}_{3} \mathrm{C}$ were uniformly distributed throughout the microstructure. For the microstructures control-rolled at heating temperatures of 900 and $1000{ }^{\circ} \mathrm{C}$ with average ferrite grain sizes of 1.34 and $1.63 \mu \mathrm{m}$, respectively, a bimodal structure
\end{abstract}


could be observed by scanning electron microscopy (SEM), which was very similar to the result of a plane-strain compression (PSC) test. Moreover, the 900 and $1000{ }^{\circ} \mathrm{C}$-heated specimens had less well developed textures primarily consisting of $\{113\}-\left\{\begin{array}{lll}4 & 411\end{array}\right\}<110>$ and $\{332\}<113>$ components, which usually developed by the transformation $(\gamma \rightarrow \alpha)$, and the $1000{ }^{\circ} \mathrm{C}$-heated specimen exhibited various textures and a low intensity of the $\{100\}<011>$ component, which was generally transformed from the $\{100\}<001>$ component of the recrystallized austenite.

Keywords: Low-carbon steel; Bimodal structure; Severe plastic deformation; Controlled-rolling process; Thermomechanical processing; Plane-strain compression

\section{Introduction}

To satisfy the social demand for lightweight construction, over the last few decades, a number of investigations on enhancing the strength and performance of metals have been carried out involving various methods of microstructure control such as solid-solution strengthening [1,2], precipitation hardening [3,4], cold work hardening [5,6], and dispersion strengthening $[7,8]$. Among these methods, grain refinement is suitable for producing high-strength materials without any additive elements, showing that a reduction in elongation is less significant than an increase in strength with superior cost performance. Thus, various studies concerning the grain refinement 
of metals including by severe plastic deformation (SPD) have also been steadily carried out [9-22]. The variation of the strength of metallic materials as a result of such grain refinement has been well established by Hall [23] and Petch [24] and many investigations still are based on the Hall-Petch equation $\left(\sigma_{y}=\sigma_{0}+k d^{-1 / 2}\right)$ [25-28]. In the grain refinement of steel and aluminum, high strength and good ductility are maintained when the grain size is between 1 and $10 \mu \mathrm{m}$. However, fracture soon begins to occur after yielding takes place during plastic deformation at ambient temperatures when the grain size is reduced to less than $1 \mu \mathrm{m}$. The uniform elongation will become almost zero when the grain size is reduced to nanometer scale, even though the strength is significantly enhanced [29,30], leading to the reduced formability of metals [31]. This indicates that it is difficult to manufacture products such as vehicle and aircraft components made of ultrafine-grained metals, particularly nanocrystalline metals, through secondary plastic deformation methods such as forging, pressing, drawing, and extrusion.

Wang et al. [32] proposed an innovative method for the intended fabrication of heterogeneous microstructures (so-called bimodal structures) to enhance ductility while retaining strength. They reported that micron-size grains (1-3 $\mu \mathrm{m})$ were dispersed in a matrix of nanosize grains $(<300 \mathrm{~nm})$ in pure $\mathrm{Cu}$ produced by multipass equal-channel angular pressing (ECAP) in conjunction with a further annealing process. The resulting microstructure exhibited significantly improved ductility while maintaining superior strength. Most recent studies on the formation of heterogeneous structures such as a bimodal structure have been performed to improve the 
mechanical properties of metals by SPD with multiple passes in conjunction with an annealing process [33-41]. However, these results exhibiting the high performance of metals have hardly been applied to industry or to mass production including that of metal strip sheets because of the high production cost, high energy consumption, and long manufacturing time required for such processes.

We have attempted to resolve these issues through a heavy-reduction single-pass controlled rolling process, which can be used to mass-produce steel strip sheets. As the first step, a heavy-reduction single-pass plane-strain compression (PSC) test, which simulates the hot-rolling process, was performed to investigate the formation mechanism of the bimodal structure and its mechanical properties using a variety of steels such as $0.01,0.1$, and $0.2 \%$ carbon steel as well as niobium steel $(0.16 \% \mathrm{C}-1.41 \% \mathrm{Mn}-0.03 \% \mathrm{Nb})$ with different deformation temperatures $[42,43]$. It was found that high-performance steels composed of equiaxed fine or ultrafine grains with uniformly dispersed cementite or fine pearlite grains were produced in all the steels. However, a bimodal structure containing a mixture of micron-size grains $(1-4 \mu \mathrm{m})$ and submicron-size grains $(<1 \mu \mathrm{m})$ could only be observed in $0.2 \%$ carbon steel: this steel exhibited an excellent balance between superior strength and marked elongation. This process is a promising means of manufacturing steel strips having a bimodal structure with industrially acceptable productivity by inducing a strain-induced transformation $(\gamma \rightarrow \alpha)$ after SPD slightly above the critical transformation temperature $\left(A_{\mathrm{c} 3}\right)$. Moreover, in the conventional controlled rolling process (Fig. 
1) [44], 6 rolling stands (F1 to F6) are required to produce a steel sheet strip, which consists of fine ferrite grains (about 4-8 $\mu \mathrm{m}$ ), with a thickness reduction from 35 to $2.3 \mathrm{~mm}$. In the heavy-reduction controlled rolling process, a thickness reduction from 35 to $2.3 \mathrm{~mm}$ could be achieved by 3 rolling stands (F1 to F3): in the first rolling stand (F1), crown and shape of a steel plate during controlled rolling process are controlled with a thickness reduction from 35 to 14.2 $\mathrm{mm}$; in the second rolling stand (F2), a bimodal structure in steel is formed with a thickness reduction from 14.2 to $2.78 \mathrm{~mm}$ (80\% thickness reduction); finally, flatness and roughness of a steel strip are controlled with a thickness reduction from 2.78 to $2.3 \mathrm{~mm}$. This is our concept of the heavy-reduction controlled rolling process and it is expected to not only reduce the production cost but also produce a high-performance steel strip with a bimodal structure in comparison with the conventional controlled rolling process. In this study, as the second step, on the basis of the previous results for each steel obtained from the PSC test, heavy-reduction single-pass controlled rolling with approximately $75 \%$ thickness reduction was conducted to investigate the optimal conditions for producing the bimodal structure in $0.2 \%$ carbon steel strips and to explore the microstructural evolution including the crystallographic texture via optical microscopy (OM), scanning electron microscopy (SEM), field-emission scanning electron microscopy (FE-SEM), and electron backscattering diffraction (EBSD). 


\section{Experimental procedure}

\subsection{Material}

$0.2 \%$ carbon steel $($ C.E. $=0.3 \%)$ was used in the present investigation for the heavy-reduction single-pass controlled rolling process. The chemical composition of low-carbon steel is shown in Table 1 . The as-received $0.2 \%$ carbon steel had ferrite-pearlite structures with an average ferrite grain size of approximately $41 \mu \mathrm{m}$, as shown in Fig. 2. The as-received steel was machined into a plate of $w 50$ or $80 \mathrm{~mm} \times t 10 \mathrm{~mm} \times l 300 \mathrm{~mm}$ for the controlled rolling process.

\subsection{Heavy-reduction single-pass controlled rolling process}

Schematic diagrams of the width-restricted heavy-reduction controlled rolling machine and the experimental procedures in the heavy-reduction controlled rolling process are presented in Figs. 3 and 4, respectively. Experimental details of the controlled rolling process are listed in Table 2. Glass lubricant was applied around the surface of the specimen, after the specimen was heated in an electric resistance furnace and held at $700,800,900$, or $1000{ }^{\circ} \mathrm{C}$, in a $\mathrm{N}_{2}$ gas atmosphere for $35 \mathrm{~min}$. Then, the heavy-reduction controlled rolling process was performed at a rolling speed of $4.2 \mathrm{~m} / \mathrm{min}$ with a mean height reduction of $70 \%$ (heating temperature of $700{ }^{\circ} \mathrm{C}$ ) or $75 \%$, corresponding to average strains of 1.4 and 1.6 and strain rates of 2.7 and $2.8 \mathrm{~s}^{-1}$, respectively. After rolling, the specimens were immediately cooled by mist cooling at a rate of $10-30{ }^{\circ} \mathrm{C} / \mathrm{s}$. 
The average strain and the strain rate during rolling are given by

$$
\begin{aligned}
& \bar{\varepsilon}=\frac{2}{\sqrt{3}} \ln (1-r), \\
& \dot{\varepsilon}=\frac{2 v_{\mathrm{r}} \sin \theta}{\mathrm{h}_{\mathrm{f}}+\mathrm{D}(1-\cos \theta)},
\end{aligned}
$$

where $r$ is the thickness reduction, $v_{\mathrm{r}}=2 \pi R n$ ( $n$ is the number of revolutions per second), $h_{\mathrm{f}}$ is the thickness of the plate after rolling, and $D$ is the diameter of the roll.

\subsection{Microstructure observation}

The specimens were etched in $2 \%$ nital solution after mechanical polishing using $\mathrm{SiC}$ papers and $1 \mu \mathrm{m}$ alumina powder, and their microstructures were observed by OM, SEM, FE-SEM, and EBSD to examine the microstructural evolution including the crystallographic texture of the specimens. The grain size was determined by analyzing SEM images.

\section{Results and discussion}

3.1 Microstructural evolution of $0.2 \%$ carbon steel with different heating temperatures examined by $O M$ and SEM after rolling test

The microstructures after controlled rolling at heating temperatures of 700 and $800{ }^{\circ} \mathrm{C}$ consisted of ferrites grains and pearlite colonies. Elongated structures were mostly observed and the fraction of elongated ferrites decreased with increasing heating temperature from 700 to 800 
${ }^{\circ} \mathrm{C}$ as shown in Figs. 5(a, e) and (b, f). On the other hand, at heating temperatures of 900 and $1000{ }^{\circ} \mathrm{C}$, above the critical transformation temperature $\left(A_{\mathrm{c} 3}\right)$ which was estimated to be $827{ }^{\circ} \mathrm{C}$, equiaxial ultrafine grains $(0.5-1 \mu \mathrm{m}$ diameter) and fine grains (about $1-4 \mu \mathrm{m}$ diameter) were present with uniformly distributed cementite or fine pearlite grains throughout the matrix. In Figs. $5(\mathrm{~d})$ and (h), which show the results after controlled rolling at a heating temperature of $1000{ }^{\circ} \mathrm{C}$, it can be observed that fine ferrites of $2-5 \mu \mathrm{m}$ diameter exist locally in the matrix. It is considered that they are generated from partially recrystallized austenite grains during the thermomechanical process. From these microstructures of each control-rolled specimen and the results of $0.2 \%$ carbon steel subjected to the PSC test at deformation temperatures from 700 to $850{ }^{\circ} \mathrm{C}$ [42], it was estimated that the actual deformation temperatures of the specimens with heating temperatures of $700,800,900$, and $1000{ }^{\circ} \mathrm{C}$ during the controlled rolling process were approximately $650,750,850$, and $950{ }^{\circ} \mathrm{C}$, respectively.

The initial coarse structure with an average ferrite grain size of about $41 \mu \mathrm{m}$ consisting of coarse ferrite and pearlite structures was transformed into fine ferrite and finely dispersed pearlite or cementite structures, and the ferrite grains were considerably refined after the single-pass heavy-reduction controlled rolling process near or above the critical transformation temperature $\left(A_{\mathrm{c} 3}\right)$. This result shows good agreement with our previous studies using $0.01,0.1$, and $0.2 \%$ carbon steels as well as a niobium steel subjected to the PSC test near or above $A_{\mathrm{c} 3}$, simulating heavy-reduction single-pass controlled rolling $[42,43]$. Furthermore, it has been well 
known that grain size was significantly reduced by the strain-induced transformation $(\gamma \rightarrow \alpha)$ in various steels during the thermomechanical treatment near $A_{\mathrm{c} 3}$ or $A_{\mathrm{r} 3}$ [46-49]. The rolling force was about 220 tons when the heavy-reduction controlled rolling process was performed using $0.2 \%$ carbon steel with $80 \mathrm{~mm}$ width of a heating temperature of $900{ }^{\circ} \mathrm{C}$ (estimated deformation temperature of $850{ }^{\circ} \mathrm{C}$ ) with $75 \%$ thickness reduction and glass lubricant, indicating that the rolling force will be approximately 2800 tons in the practical production of 1000-mm-wide strips. Fortunately, this value is not only less than the maximum capacity of a hot strip rolling mill of approximately 4000 tons $/ \mathrm{m}$ but is also similar to the estimated value (2820 tons $/ \mathrm{m})$ for the PSC-tested specimen at $850{ }^{\circ} \mathrm{C}$ with about $70 \%$ thickness reduction [42]. Thus, this rolling process is industrially realistic for manufacturing structural metal sheets. On the other hand, in the ECAP process, which is generally performed through the SPD process, a high load, sound dies, and high energy consumption are required to produce metals with ultrafine grains because ECAP is usually conducted at a low temperature with multipass processing. Moreover, ECAP has only been used in the laboratory because of its low productivity and small sample size $[15,22]$. Therefore, it is difficult to manufacture structural metal sheets using this process.

The specimens control-rolled at heating temperatures of 900 and $1000{ }^{\circ} \mathrm{C}$, which appeared to form a bimodal structure [Figs. 5(g) and (h)], were observed with a high magnification by SEM, because our final target is to manufacture a bimodal structure with a mixture of submicron-size $(<1 \mu \mathrm{m})$ and micron-size grains $(2-5 \mu \mathrm{m})$. Their SEM images and grain size distributions in 
terms of the fraction of the number of grains and the area of grains are shown in Fig. 6. In Fig. 6, it can be observed that the ultrafine ferrites in both specimens mostly consist of equiaxed grains with a size of about $1-2 \mu \mathrm{m}$ with pearlite or cementite particles finely dispersed throughout the matrix. The average ferrite grain sizes after controlled rolling at heating temperatures of 900 and $1000{ }^{\circ} \mathrm{C}$ were 1.34 and $1.64 \mu \mathrm{m}$, respectively. In Figs. 6(a) and (c), ultrafine grains with a size of less than $1 \mu \mathrm{m}$ and fine grains (1-4 $\mu \mathrm{m})$ can be observed, and the proportion of ferrite grains with a size of less than $1.25 \mu \mathrm{m}$ is $54 \%$ after controlled rolling at a heating temperature of $900{ }^{\circ} \mathrm{C}$, where the deformation temperature is estimated to be about $850{ }^{\circ} \mathrm{C}$. This result is similar to the result for $0.2 \%$ carbon steel subject to the PSC test at a deformation temperature of $850{ }^{\circ} \mathrm{C}$ [42]. In Figs. 6(b) and (d), it can also be seen that ultrafine grains with a size of less than $1 \mu \mathrm{m}$ and fine grains $(1-4 \mu \mathrm{m})$ are present in the matrix, and the proportion of ferrite grains with a size of less than $1.25 \mu \mathrm{m}$ is $38 \%$ after controlled rolling at a heating temperature of $1000{ }^{\circ} \mathrm{C}$, where the deformation temperature is estimated to be approximately $950{ }^{\circ} \mathrm{C}$. However, the grains in Fig. 6(b) are slightly larger than those in Fig. 6(a). In the specimen control-rolled at a heating temperature of $1000{ }^{\circ} \mathrm{C}$, the proportion of submicron-size grains $(<1 \mu \mathrm{m})$ decreased and that of micron-size grains $(1-4 \mu \mathrm{m})$ increased in terms of the number of grains, in comparison with those of the specimen control-rolled at a heating temperature of $900{ }^{\circ} \mathrm{C}$. Moreover, the grain size distribution was shifted slightly to right at the higher heating temperature. As can be seen in Figs. 6(c) and (d), two Gaussian distributions with mean grain sizes of 1.5 and $1.8 \mu \mathrm{m}$ can be observed 
on the basis of the proportion of the number and the area of grains, respectively. This strongly indicates the formation of a bimodal structure by the heavy-reduction single-pass controlled rolling process at heating temperatures of 900 and $1000{ }^{\circ} \mathrm{C}$, where the deformation temperatures are estimated to be approximately 850 and $950{ }^{\circ} \mathrm{C}$, respectively.

3.2 Investigation concerning crystallographic texture and misorientation angle of the specimens subjected to heavy-reduction controlled rolling process with different heating temperatures using

\section{EBSD technique}

EBSD analysis was conducted to investigate the crystallographic texture and misorientation angle of specimens subjected to controlled rolling in the initial phase (ferrite-pearlite), two-phase (ferrite-austenite), and one-phase (austenite) regions. The results of the EBSD analysis of the specimens subjected to the heavy-reduction controlled rolling process with heating temperatures of 700, 800, 900, and $1000{ }^{\circ} \mathrm{C}$ [(a) and (f) IQ (image quality) maps, (b) and (g) RD maps, (c) and (h) TD maps, (d) and (i) ND maps, and (e) and (j) (111) pole figure (left) and inverse pole figure in RD (right)] are shown in Figs. 7 and 8. Here, RD is the rolling direction, TD is the transverse direction, and ND is the direction from the surface to the center. Typically, the IQ map represents the contrast of the diffraction bands for each analysis. The brighter the gray level in the map, the better the diffraction conditions. The image quality is very sensitive to the crystal orientation and defects such as dislocations, and the EBSD pattern quality decreases when dislocations are 
piled-up at a particular location [50]. The IQ map also provides a representation of the actual microstructure, similarly to conventional scanning or optical microscopy [51]. Hence, a region with a higher dislocation density corresponds to a low image quality, shown by a dark color in an IQ map. As can be seen in Figs. $7(\mathrm{a}, \mathrm{f})$ and $8(\mathrm{a}, \mathrm{f})$, the microstructures containing pancake-shaped and elongated structures for heating temperatures of 700 and $800{ }^{\circ} \mathrm{C}$ mainly show darker contrast than the other microstructures, indicating that a high dislocation density exists near the elongated structures. The specimens with heating temperatures of 700 and $800{ }^{\circ} \mathrm{C}$ both show strong textures in the $<101>,<001>/ /$ RD and $<111>,<001>/ /$ ND directions. In the $<001>$ direction, textures are observed in all maps, and the $\gamma$-fiber in the (111) pole figure and the conventional rolling texture in the inverse pole figure in the RD can be seen as shown in Fig. 7. In general, it is well known that the textures of cold-rolled low-carbon steels primarily consist of $\alpha-(<110>/ / \mathrm{RD})$ and $\gamma-(<111>/ / \mathrm{ND})$ fibers [52-54]. However, the textures in the specimens with heating temperatures of 900 and $1000{ }^{\circ} \mathrm{C}$ are less well developed than those in the specimens with heating temperatures of 700 and $800{ }^{\circ} \mathrm{C}$, as shown in Fig. 8. Additionally, the intensity of $\gamma$-fibers decreased and the textures involving the conventional rolling texture changed with increasing heating temperature.

Misorientation maps and distributions of misorientation angles for the specimens subjected to the heavy-reduction controlled rolling process with heating temperatures of $700,800,900$, and $1000{ }^{\circ} \mathrm{C}$ are shown in Figs. 9 and 10, respectively. Here, LAGBs having a misorientation angle 
of less than $15^{\circ}$ are indicated by green and red lines. On the other hand, blue lines represent HAGBs having a misorientation of greater than $15^{\circ}$. In Fig. 9(a), which shows the result of controlled rolling in the initial phase (ferrite-pearlite) region, green and red lines are strongly concentrated near the elongated coarse grains and they are located almost everywhere. Coarse ferrites with a diameter of over $20 \mu \mathrm{m}$ still locally exist in the microstructure, although a large strain (1.4) is imposed on the specimen through the heavy-reduction single-pass controlled rolling process. The fraction of LAGBs and the average misorientation for the specimen control-rolled at a heating temperature of $700{ }^{\circ} \mathrm{C}$ are $71 \%$ and $13.8^{\circ}$, respectively, as shown in Fig. 9(b). In Fig. 9(c), which shows the result of controlled rolling in the two-phase (ferrite-austenite) region, the grains were refined in most areas but elongated ferrites can be observed in the matrix. Furthermore, green and red lines are still concentrated around the elongated ferrites. The fraction of LAGBs and the average misorientation for the specimen control-rolled at a heating temperature of $800{ }^{\circ} \mathrm{C}$ are $52 \%$ and $21.5^{\circ}$, respectively, as shown in Fig. 9(d). From results in Fig. 9, most of the misorientations for the specimens control-rolled at heating temperatures of 700 and $800{ }^{\circ} \mathrm{C}$ are less than $15^{\circ}$, indicating a high density of LAGBs. Conversely, in Fig. 10, which shows the result of controlled rolling in the one-phase (austenite) region, blue lines rather than green and red lines are mainly present in the matrix, indicating a high fraction of HAGBs. Here, a bimodal structure with a mixture of submicron-size $(<1 \mu \mathrm{m})$ and micron-size grains $(1-5 \mu \mathrm{m})$ can also be observed. The fraction of LAGBs and the average 
misorientation for the specimens control-rolled at heating temperatures of 900 and $1000{ }^{\circ} \mathrm{C}$ are $27 \%$ and $31.4^{\circ}$, and $25 \%$ and $32.6^{\circ}$, respectively, as shown in Figs. 10(b, d). The proportion of LAGBs decreased, the average misorientation increased, and the misorientation peaks became more uniform when the heating temperature was increased from 700 to $1000{ }^{\circ} \mathrm{C}$. In addition, the fraction of LAGBs for the specimen with the heating temperature of $1000{ }^{\circ} \mathrm{C}$ was significantly decreased by $46 \%$ points $(71 \rightarrow 25 \%)$, compared with that for the specimen with the heating temperature of $700{ }^{\circ} \mathrm{C}$. The microstructure was primarily composed of ultrafine grains with HAGBs at heating temperatures of 900 and $1000{ }^{\circ} \mathrm{C}$, and the microstructure was severely deformed above the critical transformation temperature $\left(A_{\mathrm{c} 3}\right)$. In Fig. 10(c), a zone of fine ferrites with a diameter of $2-5 \mu \mathrm{m}$ can be observed, which may have transformed from partially recrystallized austenite grains during the controlled rolling process.

The orientation distribution function (ODF), which specifies the frequency of occurrence of particular orientations in the three-dimensional (Euler) orientation space, is useful for investigating textures because it provides a more complete description than pole figures [53]. All the ideal orientations of the RD, ND, and TD fibers in steel can be found in the $\varphi_{2}=45^{\circ}$ section (Bunge notation) of the Euler space [55], and the $\varphi_{2}=45^{\circ}$ section can be used to identify the $\alpha-$ and $\gamma$-fibers developed by rolling [56]. Therefore, ODF analysis was adopted to clarify the change in the texture of the specimens and the ODF sections with $\varphi_{2}=45^{\circ}$ for the specimens subjected to the heavy-reduction controlled rolling process at different heating temperatures are 
shown in Fig. 11. As can be seen in Fig. 11, the textures are significantly changed and that the maximum value of the ODF map is reduced by increasing the heating temperature from 700 to $1000{ }^{\circ} \mathrm{C}$. In Fig. 11(a), shows the specimen subjected to controlled rolling in the initial phase (ferrite-pearlite), textures composed of $\{111\}<110>$ and $\{111\}<112>$ components are strongly developed, which correspond to <111>//ND $\gamma$-fibers, and there are $\alpha$-fibers with $<110>/ / \mathrm{RD}$ stretching from the $\{111\}<110>$ to $\{001\}<110>$ components. In Fig. 11(b), which shows the specimen subjected to controlled rolling in the two-phase (ferrite-austenite) region, the intensity of $\gamma$-fibers is reduced and the intensity of $\alpha$-fibers consisting mainly of $\{113\}-\{4411\}<110>$ components is sharper in comparison with the $700{ }^{\circ} \mathrm{C}$-heated specimen. Moreover, an increase in the sharpness of the $\{001\}<110\rangle$ component and a weak $\{332\}<113>$ component can be observed in the $800{ }^{\circ} \mathrm{C}$-heated specimen. In Figs. 11(c, d), which show the specimens subjected to controlled rolling in the one-phase (austenite) region, which has estimated deformation temperatures of 850 and $950{ }^{\circ} \mathrm{C}$, respectively, the components near $\{112\}<110>$ and around $\{113\}<110>$ are much more developed than the other textures in both specimens, and the $\gamma$-fibers in both specimens are much weaker than those in the 700 - and $800{ }^{\circ} \mathrm{C}$-heated specimens. The $\{001\}<110>$ component is present as shown in Fig. 11(d).

The microstructure of the specimen held for $35 \mathrm{~min}$ at a heating temperature of $700{ }^{\circ} \mathrm{C}$ still retained its initial structure (ferrite-pearlite phases) because the heating temperature was below $A_{\mathrm{c} 1}$ (estimated to be $725^{\circ} \mathrm{C}$ ). There were many dislocations, which were introduced inside the 
microstructure through the controlled rolling process. This process formed fine ferrites, and fine pearlite or cementite particles from the coarse pearlite lamellae as well as substructures such as subgrains in the ferrites instead of generating new grains with HAGBs because of the high stacking fault energy of ferrite $[42,43,57]$. This led to not only an increase in the fraction of LAGBs but also the generation of strongly developed textures such as $\alpha-(<110>/ / \mathrm{RD})$ and $\gamma-(<111>/ / \mathrm{ND})$ fibers in the ferrite after the heavy-reduction controlled rolling process [Figs. 9(a, b) and 11(a)]. Also, elongated coarse ferrites of over $20 \mu \mathrm{m}$ diameter having LAGBs (mostly subgrains) were present, as shown in Fig. 9(a). This may be attributed to insufficient strain $(\varepsilon \approx$ 1.4 at $\mathrm{r}=70 \%$ ) applied to the specimen to induce recrystallization in the initial coarse grains (about $41 \mu \mathrm{m}$ ).

By increasing the heating temperature from 700 to $800{ }^{\circ} \mathrm{C}$, the initial structure (ferrite-pearlite phases) is transformed to a ferrite-austenite structure because $A_{\mathrm{c} 1}$ is less than 800 ${ }^{\circ} \mathrm{C}$. The estimated fraction of ferrite is approximately $60 \%$ (C.E. $=0.3 \%$ at $A_{\mathrm{e}}$ ) when the deformation temperature is about $750{ }^{\circ} \mathrm{C}$. Various dislocations were introduced inside the microstructure through the controlled rolling process. A strain-induced transformation $(\gamma \rightarrow \alpha)$ occurred in the austenite and at the $\gamma / \alpha$ interface with a high dislocation density during mist cooling, resulting in fine ferrite grains. On the other hand, elongated structures having LAGBs formed in the ferrites. In the textures, $\alpha-(<110>/ / \mathrm{RD})$ and $\gamma-(<111>/ / \mathrm{ND})$ fibers developed from the untransformed ferrite, and ferrite textures having $\{113\}-\left\{\begin{array}{lll}4 & 41\end{array}\right\}<110>$ and $\{332\}<113>$ 
components were transformed from the austenite textures with $\{112\}<111>$ and $\{110\}<112>$ components, respectively [Figs. 9(c, d) and 11(b)] [58].

When the heating temperature was increased from $800{ }^{\circ} \mathrm{C}$ to $900{ }^{\circ} \mathrm{C}$, the ferrite-austenite (two phase region) completely transformed to austenite (single phase) because the temperature exceeded $A_{\mathrm{c} 3}$ (estimated to be $\left.827{ }^{\circ} \mathrm{C}\right)$. Under these conditions, strain $(\varepsilon \approx 1.6, \mathrm{r}=75 \%)$ was imposed on the specimen by the controlled rolling process, leading to a severely deformed microstructure containing many dislocations. In particular, grain boundaries can serve as not only barriers preventing the motion of dislocations and causing their accumulation $[59,60]$ but also preferential nucleation sites $[46,61]$, generating considerable nucleation at grain boundaries with triple junctions having a higher relatively dislocation density than in the grain interior. In contrast, little nucleation took place within the grains during the strain-induced transformation $(\gamma \rightarrow \alpha)$ induced by the heavy-reduction controlled rolling process. Consequently, the microstructure might consist of heterogeneous structures with fine grains $(1-3 \mu \mathrm{m})$ at the grain interior and submicron-size grains $(<1 \mu \mathrm{m})$ at the grain boundaries. Additionally, the textures

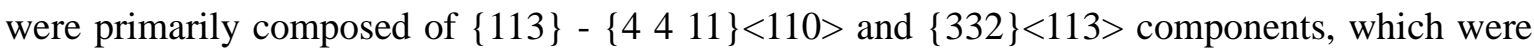
usually transformed from the austenite texture with $\{112\}<111>$ and $\{110\}<112>$ components, which mostly developed in the temperature of non-recrystallization, respectively [Fig. 11(c)] [58]. The specimen control-rolled at a heating temperature of $1000{ }^{\circ} \mathrm{C}$ showed almost the same behavior as that control-rolled at a heating temperature of $900{ }^{\circ} \mathrm{C}$. However, partial 
recrystallization occurred in the austenite owing to the high deformation temperature (estimated to be $\left.950{ }^{\circ} \mathrm{C}\right)$ and the high imposed strain $(\varepsilon \approx 1.6, \mathrm{r}=75 \%)$. This led to a region of fine ferrite grains $(2-5 \mu \mathrm{m})$ after the heavy-reduction single-pass controlled rolling process. Fukuda et al. [62] revealed that a heterogeneous structure with a mixed structure of coarse and fine grains is formed from a partially recrystallized austenite structure in various steels including plain-carbon steel by the controlled rolling process in the range of non-recrystallization temperatures at $\mathrm{r}=75 \%$. It is difficult for recrystallization to occur throughout the microstructure of plain-carbon steels, unless a sufficient holding time is provided after rolling at 33\% reduction [63]. There are much fewer nucleation sites in the recrystallized grains than in severely deformed structures during the controlled rolling, since the recrystallized grains form a new set of strain-free and equiaxed grains with low dislocation densities [64]. Moreover, as can be seen in Fig. 11(d), a $\{100\}<011>$ component with low intensity was present, which is commonly transformed from the $\{100\}<001>$ component of recrystallized austenite [58]. This is evidence that partial recrystallization occurred at a heating temperature of $1000{ }^{\circ} \mathrm{C}$. Accordingly, the microstructure might consist of heterogeneous structures with fine grains $(2-5 \mu \mathrm{m})$ formed from the partially recrystallized austenite grains and ultrafine grains $(0.5-3 \mu \mathrm{m})$ generated by the strain-induced transformation $(\gamma \rightarrow \alpha)$. With regard to the specimens with heating temperatures of 900 and 1000 ${ }^{\circ} \mathrm{C}$, the formation mechanism of the bimodal structure is schematically illustrated in Fig. 12, and a schematic illustration of the three stages of the controlled rolling process and the change in the 
microstructure with the deformation in each stage (the temperature ranges of recrystallization, non-recrystallization, and two phases) are shown in Fig. 13, which is taken from the paper of Tanaka [65].

\section{Conclusions}

A heavy-reduction single-pass controlled rolling process was conducted to investigate the microstructure evolution including the crystallographic texture and to clarify the formation mechanism of a bimodal structure in $0.2 \%$ carbon steel. The major results and conclusions of this study are summarized as follows:

1. The microstructure with HAGBs was significantly refined upon performing the single-pass heavy-reduction controlled rolling process around the critical transformation temperature $\left(A_{\mathrm{c} 3}\right)$, while elongated grains with LAGBs such as subgrains were mainly formed by the controlled rolling process near $A_{\mathrm{c} 1}$. The proportion of LAGBs in the specimens heated at 900 and $1000{ }^{\circ} \mathrm{C}$ markedly decreased by about $45 \%$ points $(71 \rightarrow 27 \%$ and $25 \%)$ compared with the specimen heated at $700{ }^{\circ} \mathrm{C}$, and the misorientation peaks became more uniform than those of the specimens heated at 700 and $800{ }^{\circ} \mathrm{C}$.

2. The average ferrite grain sizes after the controlled rolling process at heating temperatures of 900 and $1000{ }^{\circ} \mathrm{C}$ were 1.34 and $1.63 \mu \mathrm{m}$, respectively. Two Gaussian distributions with mean 
grain sizes of 1.5 and $1.8 \mu \mathrm{m}$ were observed on the basis of the proportion of the number and the area of grains, respectively, indicating the formation of a bimodal structure in $0.2 \%$ carbon steel during the controlled rolling process.

3. In the textures, the $\alpha-(<110>/ / \mathrm{RD})$ and $\gamma-(<111>/ / \mathrm{ND})$ fibers in the $700{ }^{\circ} \mathrm{C}$-heated specimens were considerably developed from the untransformed ferrite, and the strongly developed textures having $\{113\}-\left\{\begin{array}{lll}4 & 4 & 11\end{array}\right\}<110>$ and $\{332\}<113>$ components in the $800{ }^{\circ} \mathrm{C}$-heated specimen were commonly transformed from the austenite texture with $\{112\}<111\rangle$ and $\{110\}<112>$, respectively. On the other hand, both the 900 - and $1000{ }^{\circ} \mathrm{C}$-heated specimens had less well developed textures consisting of $\{113\}-\left\{\begin{array}{lll}4 & 4 & 11\end{array}\right\}<110>$ and $\{332\}<113>$ components. In particular, the $1000{ }^{\circ} \mathrm{C}$-heated specimen had various textures and a low intensity of $\{100\}<011>$ components, which were generally transformed from $\{100\}<001>$ components of the recrystallized austenite.

\section{Acknowledgements}

This research was supported by Japan Science and Technology Agency (JST) under

Collaborative Research Based on Industrial Demand "Heterogeneous Structure Control: Towards Innovative Development of Metallic Structural Materials" and the Japan Society for the Promotion of Science for Young Scientists. 


\section{References}

[1] H. Somekawa, Y. Osawa, T. Mukai, Scr. Mater. 55 (2006) 593-596.

[2] T.J. Rupert, J.C. Trenkle, C.A Schuh, Acta Mater. 59 (2011) 1619-1631.

[3] D.N. Seidman, E.A. Marquis, D.C. Dunand, Acta Mater. 50 (2002) 4021-4035.

[4] D.A. Terentyev, G. Bonny, L. Malerba, Acta Mater. 56 (2008) 3229-3235.

[5] G. Saller, K. Spiradek-Hahn, C. Scheu, H. Clemens, Mater. Sci. Eng. A 427 (2006) 246-254.

[6] A.A. Benzerga, Y. Bréchet, A. Needleman, E.V. Giessen, Acta Mater. (53) 2005 4765-4779.

[7] J.F. Nie, Scripta Mater. 48 (2003) 1009-1015.

[8] M.J. Alinger, G.R. Odette, D.T. Hoelzer, Acta Mater. 57 (2009) 392-406.

[9] P.J. Hurley, P.D. Hodgson, Mater. Sci. Eng. A 302 (2001) 206-214.

[10] D.H. Shin, I.Y. Kim, J.R. Kim, K.T. Park, Acta Mater. 49 (2001) 1285-1292.

[11] C.C. Koch, Scr. Mater. 49 (2003) 657-662.

[12] R. Song, D. Ponge, D. Raabe, R. Kaspar, Acta Mater. 53 (2005) 845-858.

[13] A. Das, G. Liu, Z. Fan, Mater. Sci. Eng. A 419 (2006) 349-356.

[14] M.A. Meyers, A. Mishra, D.J. Benson, Prog. Mater. Sci. 51 (2006) 427-556.

[15] A. Azushima, R. Kopp, A. Korhonen, D.Y. Yang, F. Micari, G.D. Lahoti, P. Groche, J. Yanagimoto, N. Tsuji, A. Rosochowski, A. Yanagida, CIRP Ann. 57 (2008) 716-735. 
[16] J. Yanagimoto, S. Sugiyama, A. Yanagida, N. Iwamura, M. Ishizuka, J. Mater. Proc. Technol. 209 (2009) 679-685.

[17] T.K. Lee, C.H. Park, D.L. Lee, C.S. Lee, Mater. Sci. Eng. A 528 (2011) 6558-6564.

[18] J. Yanagimoto, J. Tokutomi, K. Hanazaki, N. Tsuji, CIRP Ann. 60 (2011) 279-282.

[19] J. Tokutomi, K. Hanazaki, N. Tsuji, J. Yanagimoto, J. Mater. Proc. Technol. 212 (2012) 2505-2513.

[20] K. Hanazaki, J. Tokutomi, J. Yanagimoto, N. Tsuji, Mater. Sci. Eng. A 534 (2012) 720-723.

[21] J. Yanagimoto, S. Sugiyama, S. Kawando, A. Yanagida, Mater. Trans. JIM 53 (2012) 2-7.

[22] Y. Estrin, A. Vinogradov, Acta Mater. 61 (2013) 782-817.

[23] E.O. Hall, Proc. Phys. Soc. B 64 (1951) 747-753.

[24] N.J. Petch, J. Iron. Steel. Inst. 174 (1953) 25-28.

[25] R.A. Masumura, P.M. Hazzledine, C.S. Pande, Acta Mater. 46 (1998) 4527-4534.

[26] N. Hansen, Scr. Mater. 51 (2004) 801-806.

[27] A. Loucif, R.B. Figueiredo, T. Baudin, F. Brisset, R. Chemam, T.G. Langdon, Mater. Sci. Eng. A 532 (2012) 139-145.

[28] I. Toda-Caraballo, E.I. Galindo-Nava, P.E.J. Rivera-Díaz-del-Castillo, Acta Mater. 75 (2014) 287-296.

[29] S. Takaki, K. Kawasaki, Y. Kimura, J. Mater. Proc. Technol. 117 (2001) 359-363.

[30] N. Tsuji, Y. Ito, Y. Saito, Y. Minamino, Scr. Mater. (47) 2002 893-899. 
[31] O. Saray, G. Purcek. I. Karaman, H.J. Maier, Metall. Mater. Trans. A 44 (2013) 4194-4206.

[32] Y.M. Wang, M.W. Chen, F.H. Zhou, E. Ma, Nature 419 (2002) 912-915.

[33] H. Azizi-Alizamini, M. Militzer, W.J. Poole, Scr. Mater. 57 (2007) 1065-1068.

[34] G.H. Zahid, Y. Huang, P.B. Prangnell, Acta Mater. 57 (2009) 3509-3521.

[35] K.S. Raju, V.S. Sarma, A. Kauffmann, Z. Hegedűs, J. Gubicza, M. Peterlechner, J.

Freudenberger, G. Wilde, Acta Mater. 61 (2013) 228-238.

[36] M.C. Zhao, T. Hanamura, H. Qiu, K. Yang, Metall. Mater. Trans. A 37 (2006) 1657-1664.

[37] M.C. Zhao, T. Hanamura, F. Yin, H. Qiu, K. Nagai, Metall. Mater. Trans. A 39 (2008) $1692-1701$.

[38] T.S. Wang, F.C. Zhang, M. Zhang, N. Lv, Mater. Sci. Eng. A 485 (2008) 456-460.

[39] S.H. Xia, L.V. Vychigzhanina, J.T. Wang, I.V. Alexandrov, A.V. Sharafutdinov, Mater. Sci. Eng. A 490 (2008) 471-476.

[40] S. Patra, Sk. Md. Hasan, N. Narasaiah, D. Chakrabarti, Mater. Sci. Eng. A 538 (2012) $145-155$.

[41] A. Karmakar, A. Karani, S. Patra, D. Chakrabarti, Metall. Mater. Trans. A 44 (2013) 2041-2052.

[42] H.W. Park, J. Yanagimoto, Mater. Sci. Eng. A 567 (2013) 29-37.

[43] H.W. Park, J. Yanagimoto, Mater. Sci. Eng. A 607 (2014) 542-550.

[44] T. Morimoto, R. Kurahashi, I. Chikushi, J. Yanagimoto, Tetsu-to-Hagane 88 (2002) 747-754. 
(In Japanese)

[45] G.E. Dieter. Mechanical Metallurgy, 3rd edition, McGraw-Hill, New York, 1986.

[46] J.K. Choi, D.H. Seo, J.S. Lee, K.K. Um, W.Y. Choo, ISIJ Int. 43 (2003) 746-754.

[47] R. Song, D. Ponge, D. Raabe, J.G. Speer, D.K. Matlock, Mater. Sci. Eng. A 441 (2006) 1-17.

[48] K. Nagato, S. Sugiyama, A. Yanagida, J. Yanagimoto, Mater. Sci. Eng. A 478 (2008) $376-383$.

[49] K. Mukherjee, S.S. Hazra, M. Militzer, Metall. Mater. Trans. A 40 (2009) 2145-2159.

[50] C.G. Panait, A. Zielinska-Lipiec, T. Koziel, A. Czyrska-Filemonowicz, A.F. Gourgues-Lorezon, W. Bendic, Mater. Sci. Eng. A 527 (2010) 4062-4069.

[51] A.P. Zhilyaev, G.V. Nurislamova, B.K. Kim, M.D. Baro, J.A. Szpunar, T.G. Langdon, Acta Mater. 51 (2003) 753-765.

[52] U.V. Schlippenbach, F. Emren, K. Lücke, Acta Metall. 34 (1986) 1289-1301.

[53] R.K. Ray, J.J. Jonas, R.E. Hook, Int. Mater. Rev. 39 (1994) 129-172.

[54] S.H. Choi, Y.S. Jin, Mater. Sci. Eng. A 371 (2004) 149-159.

[55] L.S. Toth, J.J. Jonas, D. Daniel, R.K. Ray, Metall. Trans. A 21 (1990) 2985-3000.

[56] A.A. Gazder, M. Sánchez-Araiza, J.J. Jonas, E.V. Pereloma, Acta Mater. 59 (2011) $4847-4865$.

[57] A. Belyakov, R. Kaibyshev, T. Sakai, Metall. Mater. Trans. A 29 (1998) 161-167. 
[58] R.K. Ray, J.J. Jonas, Int. Mater. Rev. 35 (1990) 1-38.

[59] Z. Shen, R.H. Wagoner, W.A.T. Clark, Scr. Metall. 20 (1986) 921-926.

[60] R. Schouwenaars, M. Seefeldt, P.V. Houtte, Acta Mater. 58 (2010) 4344-4353.

[61] H. Miura, T. Sakai, H. Hamaji, J.J. Jonas, Scr. Mater. 50 (2004) 65-69.

[62] M. Fukuda, T. Hashimoto, K. Kunishige, Tetsu-to-Hagane 13 (1972) 1832-1847. (In Japanese)

[63] I. Kozasu, T. Shimizu, H. Kubota, Transactions ISIJ 11 (1971) 367-375.

[64] W.D. Callister, Fundamentals of Materials Science and Engineering, 5th edition, John Wiley and Sons, Inc., New York, 2000.

[65] T. Tanaka, Int. Metall. Rev. 4 (1981) 185-212. 
Table 1 The chemical composition of $0.2 \%$ carbon steel used in the controlled rolling process (mass \%).

\begin{tabular}{cccccccccc}
\hline $\mathrm{C}$ & $\mathrm{Si}$ & $\mathrm{Mn}$ & $\mathrm{P}$ & $\mathrm{S}$ & $\mathrm{Cr}$ & $\mathrm{Ni}$ & $\mathrm{V}$ & $\mathrm{Mo}$ & $\mathrm{Fe}$ \\
\hline 0.213 & 0.25 & 0.47 & $<0.005$ & 0.0012 & 0.01 & 0.02 & 0.01 & 0.01 & Bal. \\
\hline
\end{tabular}

Table 2 Experimental details of controlled rolling process.

\begin{tabular}{cc}
\hline Conditions (width) & Reduction ratio, \% \\
\hline $700{ }^{\circ} \mathrm{C}(50 \mathrm{~mm})$ & 70 \\
\hline $800{ }^{\circ} \mathrm{C}(80 \mathrm{~mm})$ & 75 \\
\hline $900{ }^{\circ} \mathrm{C}(80 \mathrm{~mm})$ & 75 \\
\hline $1000{ }^{\circ} \mathrm{C}(80 \mathrm{~mm})$ & 75 \\
\hline
\end{tabular}




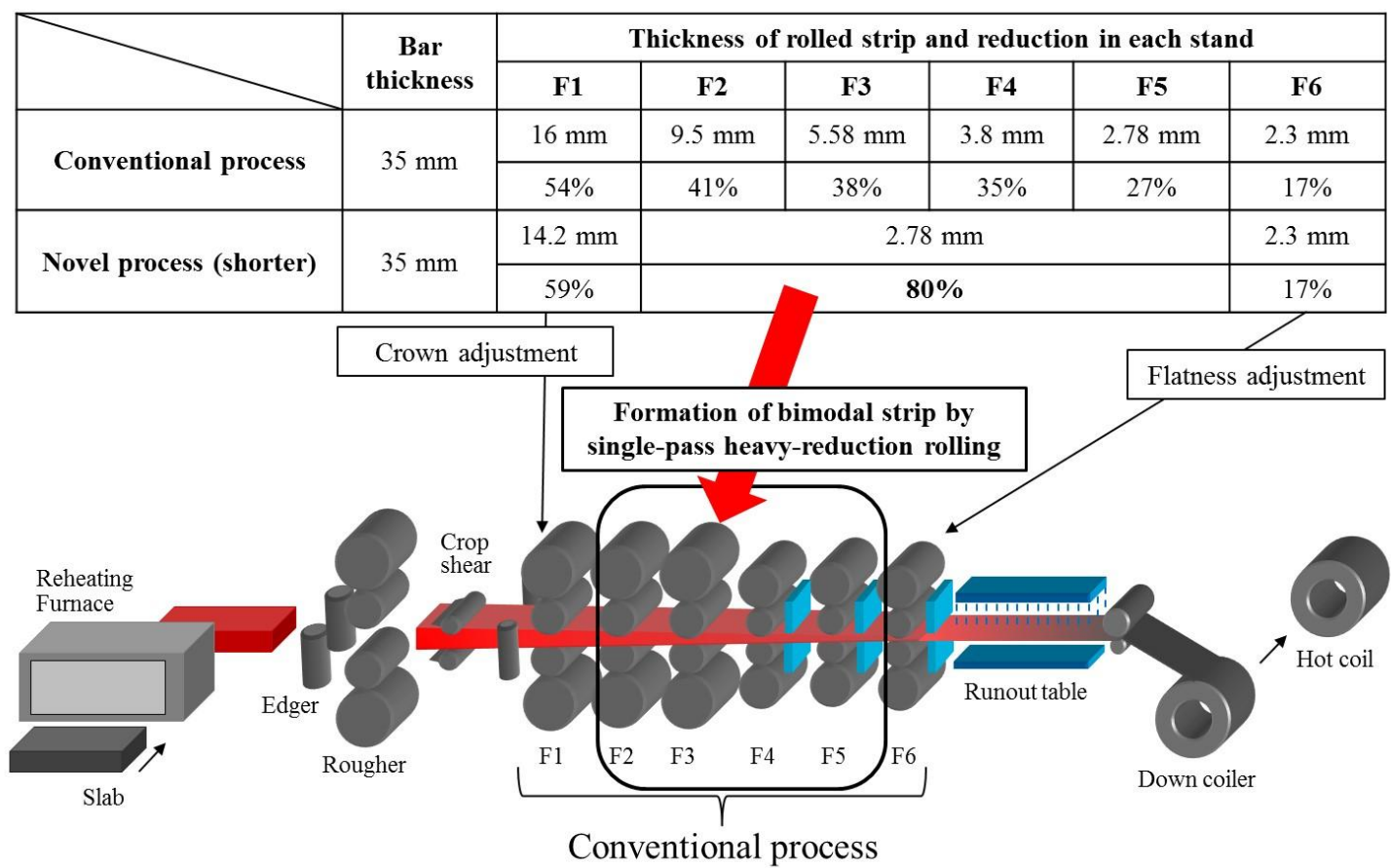

Fig. 1. Schematic diagram of a novel process: single stand to form the bimodal strip undertakes a role of four stands (F2-F5) in conventional tandem hot strip mill, and realizes the manufacturing of steel coil with bimodal microstructure within a shorter process. 


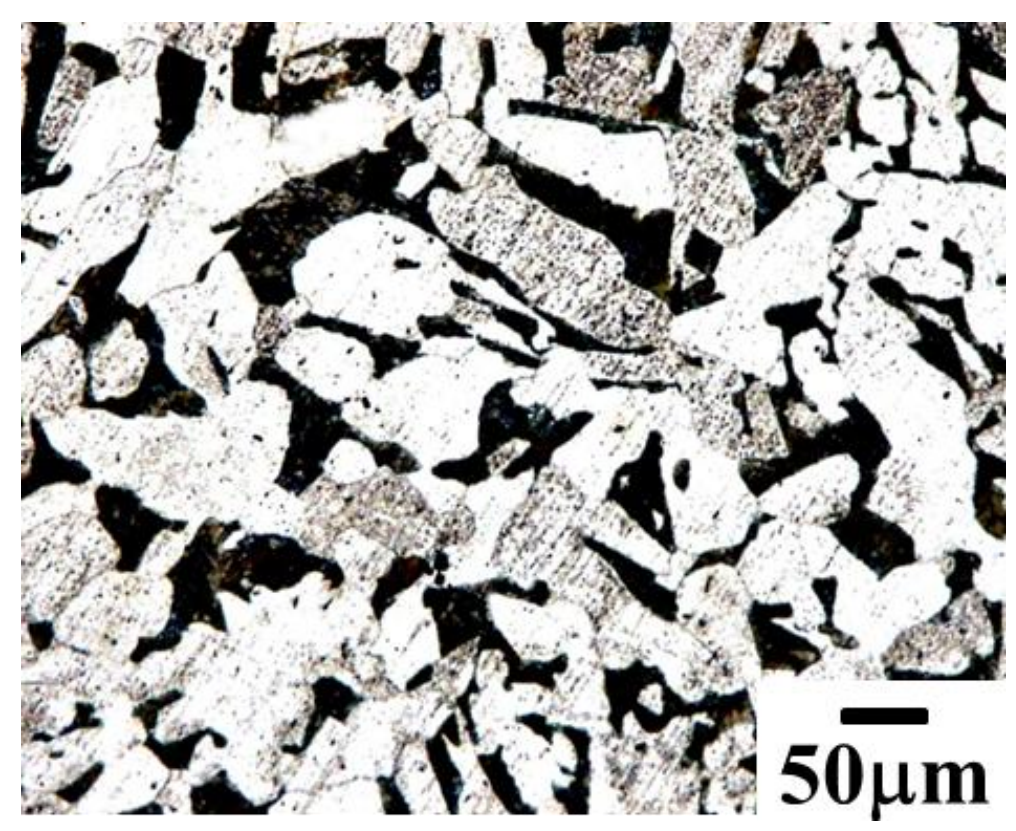

Fig. 2. Microstructure of as-received $0.2 \%$ carbon steel. 


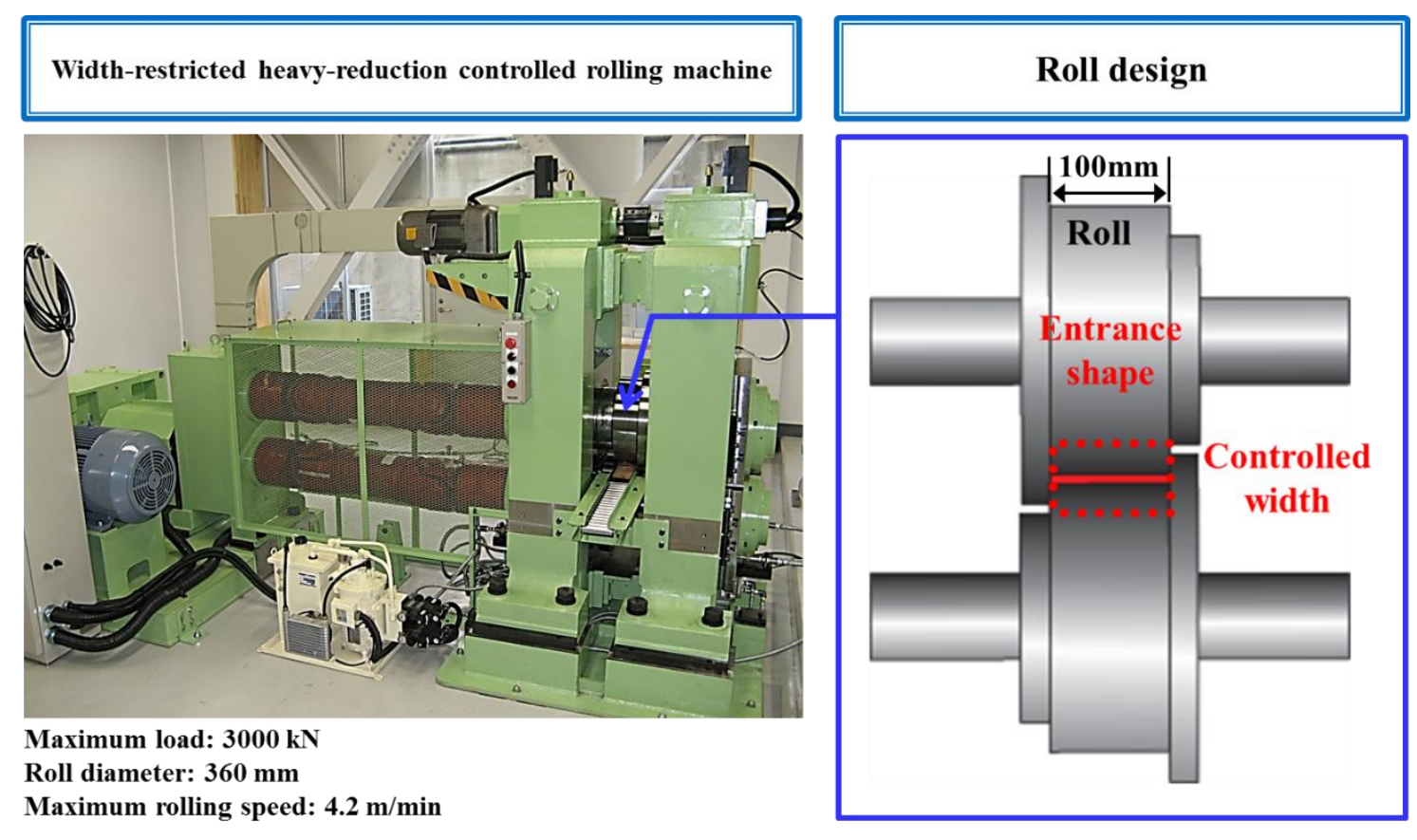

Fig. 3. A photograph and a schematic diagram of width-restricted heavy-reduction controlled rolling machine. 


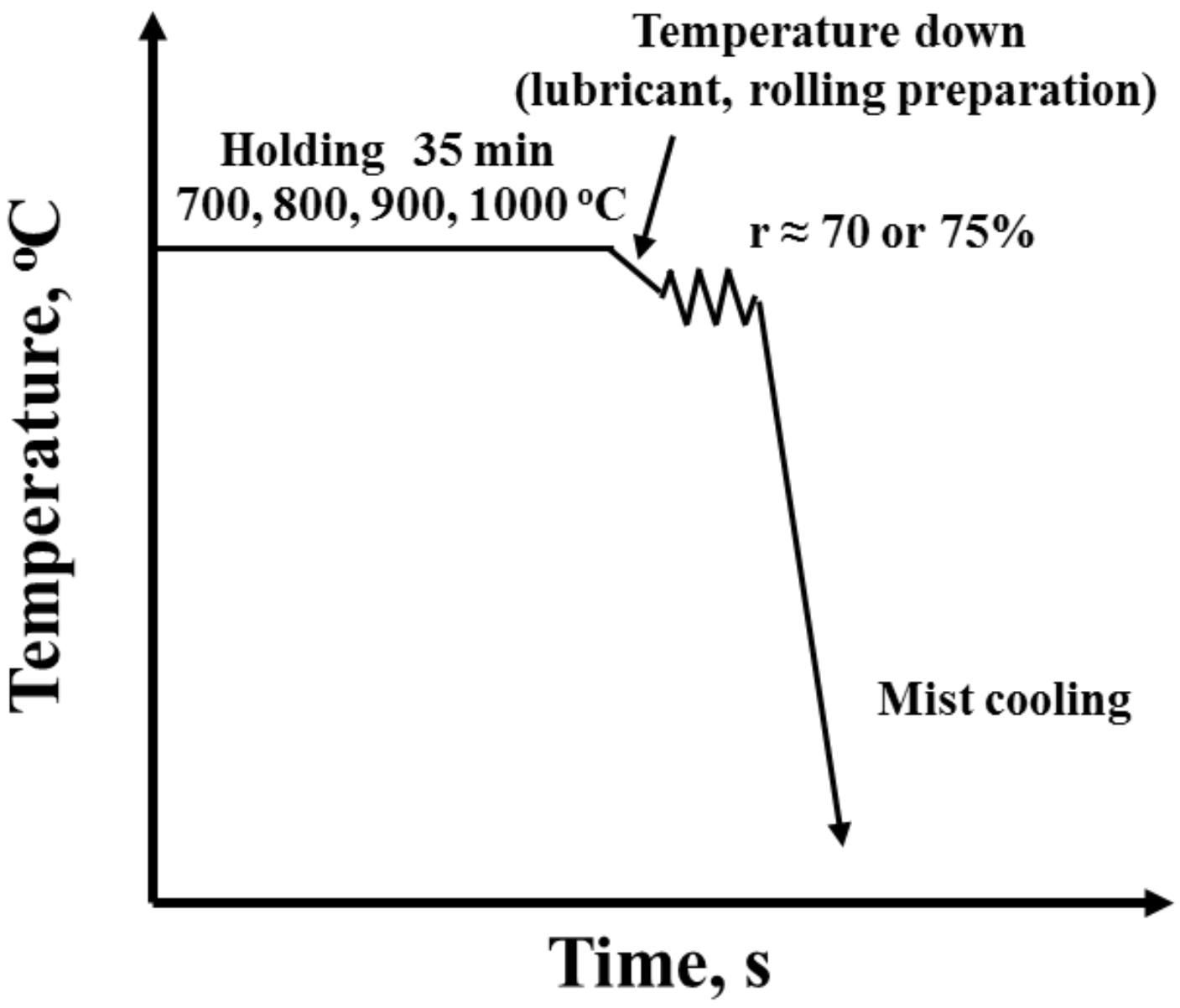

Fig. 4. Schematic diagram of experimental procedures in the heavy-reduction controlled rolling process. 

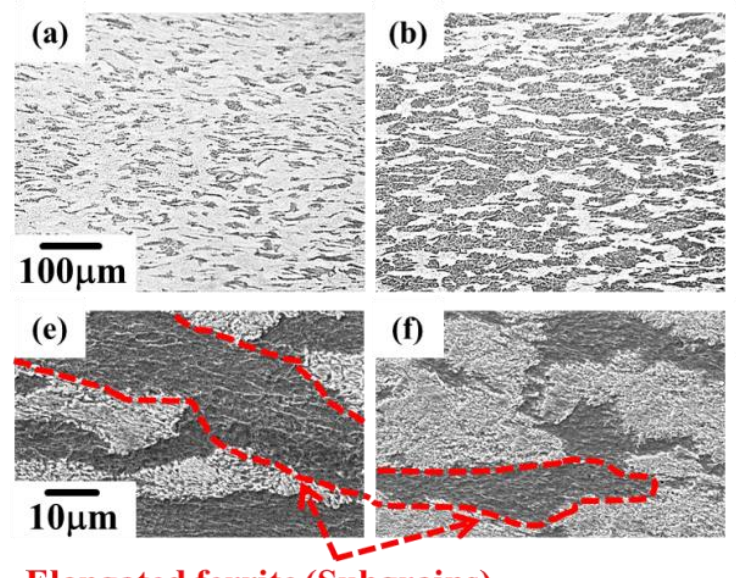

Elongated ferrite (Subgrains) (c)

(d)

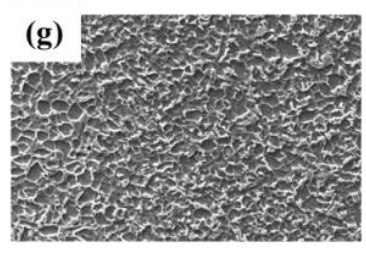

(h)

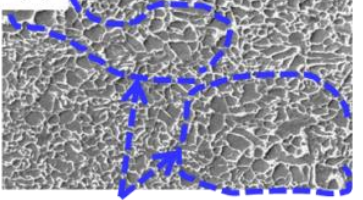

Fine grains $(2-5 \mu \mathrm{m})$ from partially recrystallized $\gamma$

Fig. 5. Microstructures of $0.2 \%$ carbon steel subjected to heavy-reduction controlled rolling process at heating temperatures of (a), (e) $700{ }^{\circ} \mathrm{C}$, (b), (f) $800{ }^{\circ} \mathrm{C}$, (c), (g) $900{ }^{\circ} \mathrm{C}$, and (d), (h) $1000{ }^{\circ} \mathrm{C}$. 

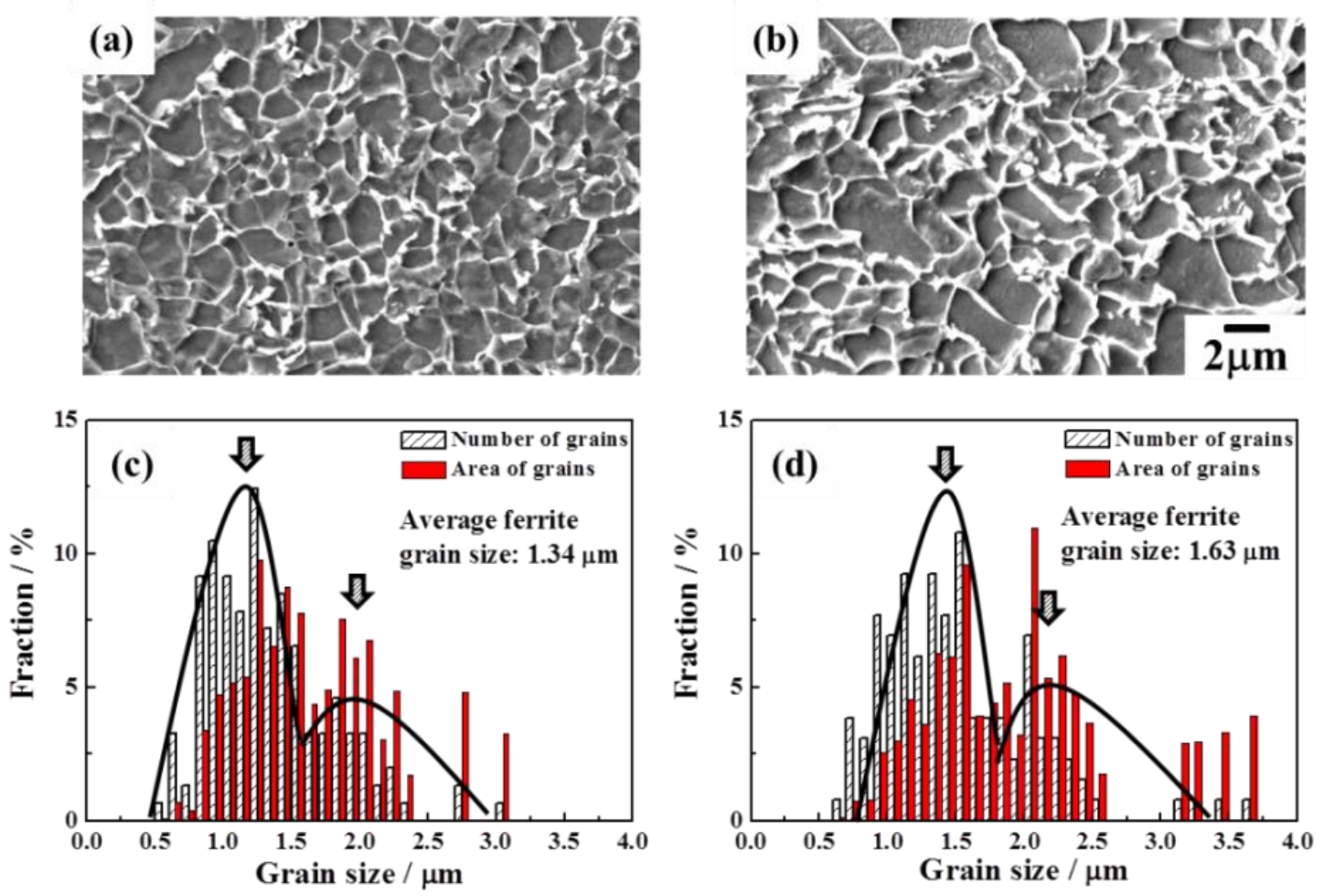

Fig. 6. SEM images and distributions of ferrite grain size of $0.2 \%$ carbon steel after heavy-reduction controlled rolling process with heating temperatures of (a, c) $900{ }^{\circ} \mathrm{C}$, $\mathrm{GS}_{\mathrm{ave}}=1.34 \mu \mathrm{m}$ and (b, d) $1000{ }^{\circ} \mathrm{C}, \mathrm{GS}_{\mathrm{ave}}=1.63 \mu \mathrm{m}$. 


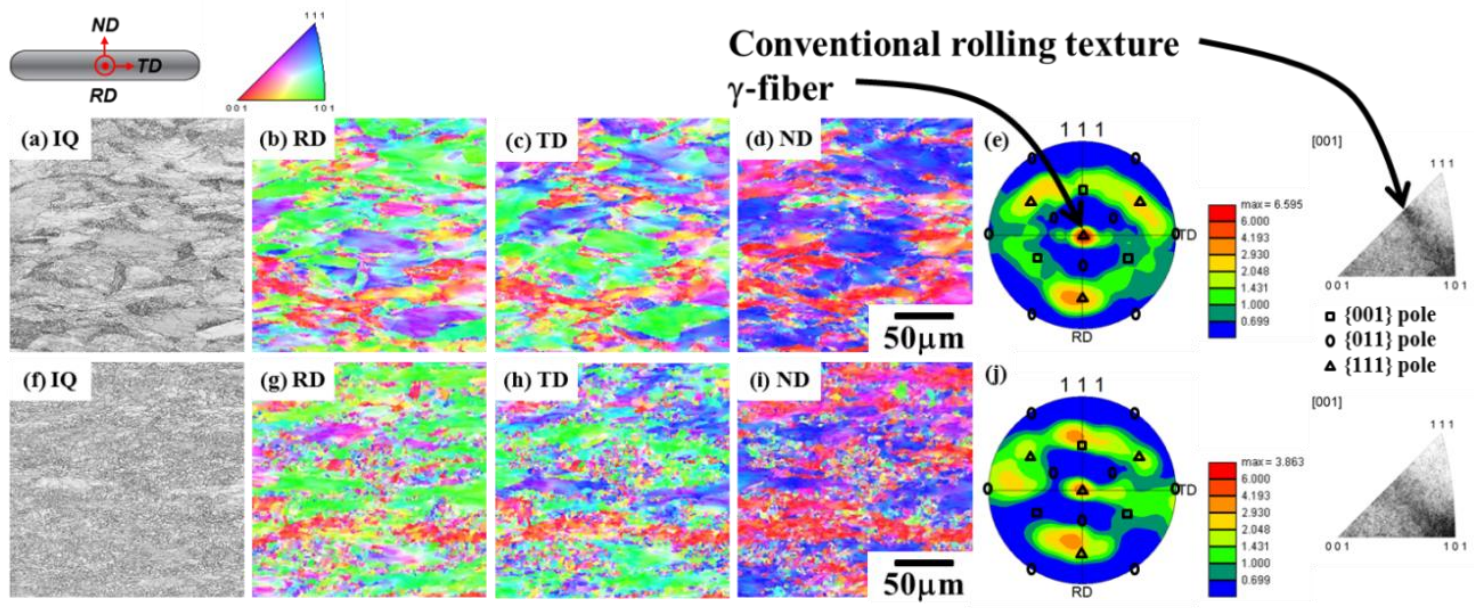

Fig. 7. EBSD analysis of the specimens subjected to heavy-reduction controlled rolling process with heating temperatures of (a)-(e) $700{ }^{\circ} \mathrm{C}$ and (f)-(j) $800{ }^{\circ} \mathrm{C}$ : (a, f) IQ maps, (b, g) RD maps, (c, h) TD maps, (d, i) ND maps, and (e, j) the (111) pole figure (left) and inverse pole figure in RD (right). 


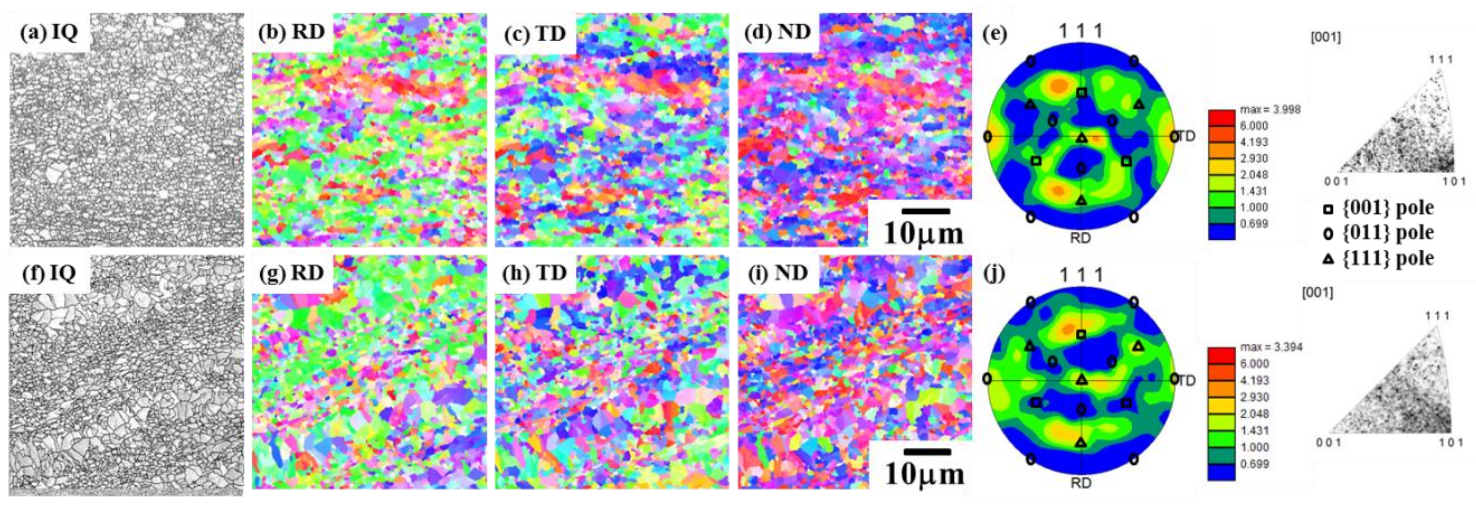

Fig. 8. EBSD analysis of the specimens subjected to heavy-reduction controlled rolling process with heating temperatures of (a)-(e) $900{ }^{\circ} \mathrm{C}$ and (f)-(j) $1000{ }^{\circ} \mathrm{C}$ : (a, f) IQ maps, (b, g) RD maps, (c, h) TD maps, (d, i) ND maps, and (e, j) the (111) pole figure (left) and inverse pole figure in $\mathrm{RD}$ (right). 

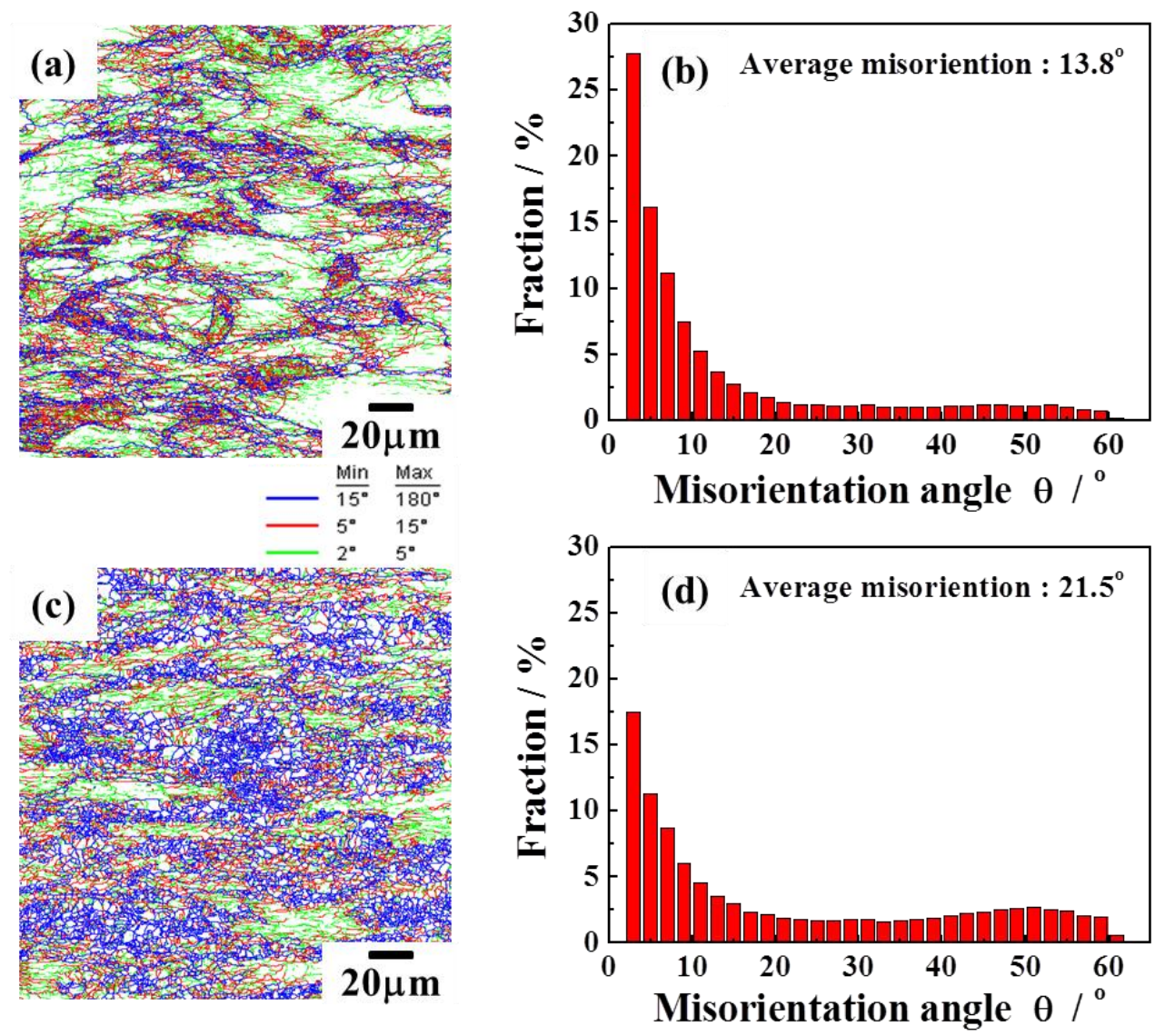

Fig. 9. Misorientation maps and distributions of misorientation angles for the specimens subjected to heavy-reduction controlled rolling process with different heating temperatures: (a, b) $700{ }^{\circ} \mathrm{C}, f_{\mathrm{LAGB}}(2 \leq \theta<15)=71 \%, \theta_{\mathrm{ave}}=13.8^{\circ}$ and (c, d) $800{ }^{\circ} \mathrm{C}$, $f_{\mathrm{LAGB}}(2 \leq \theta<15)=52 \%, \theta_{\mathrm{ave}}=21.5^{\circ}$. 

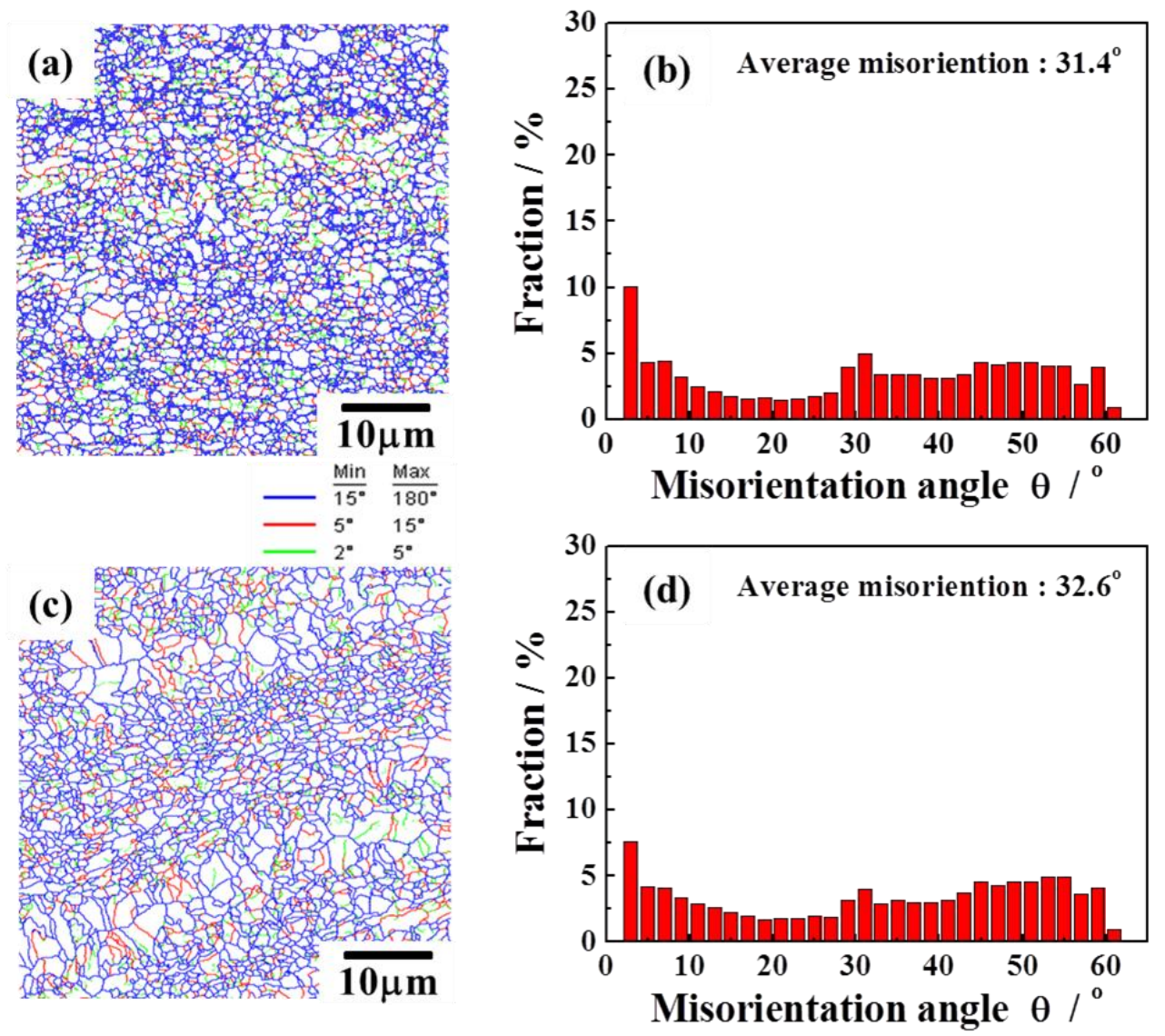

Fig. 10. Misorientation maps and distributions of misorientation angles for the specimens subjected to heavy-reduction controlled rolling process with different heating temperatures: (a, b) $900{ }^{\circ} \mathrm{C}, f_{\mathrm{LAGB}}(2 \leq \theta<15)=27 \%, \theta_{\mathrm{ave}}=31.4^{\circ}$ and (c, d) $1000{ }^{\circ} \mathrm{C}$, $f_{\mathrm{LAGB}}(2 \leq \theta<15)=25 \%, \theta_{\mathrm{ave}}=32.6^{\mathrm{O}}$. 

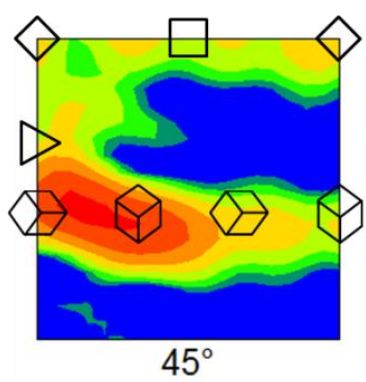

(a)

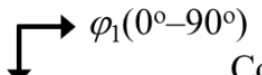

$\phi\left(0^{\circ}-90^{\circ}\right)$

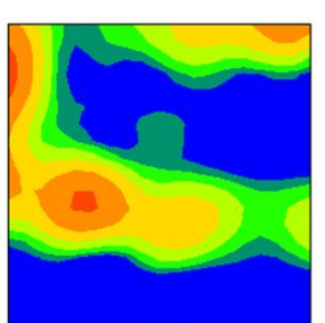

$45^{\circ}$

(b)

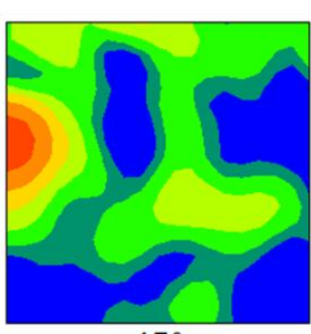

$45^{\circ}$

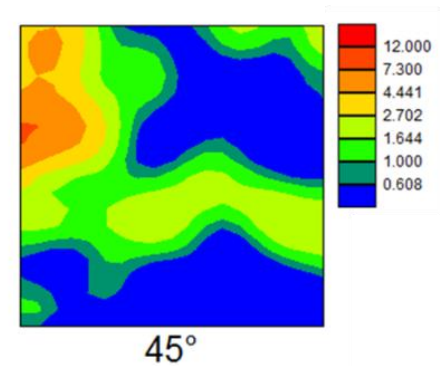

(d)

Constant angle: $\varphi_{2}=45^{\circ}$

$\diamond\{001\}<110>\square\{001\}<100>D\{112\}<110>$ $\bigotimes\{111\}<110>\bigotimes\{111\}<112>$

Fig. 11. ODF sections with $\varphi_{2}=45^{\circ}$ for the specimens subjected to heavy-reduction controlled rolling process with heating temperatures of (a) $700\left(\max _{\mathrm{v}}=14.2\right)$, (b) 800 $\left(\max _{\mathrm{v}}=9.8\right)$, (c) $900\left(\max _{\mathrm{v}}=8.7\right)$, and (d) $1000{ }^{\circ} \mathrm{C}\left(\max _{\mathrm{v}}=8.2\right)$. 


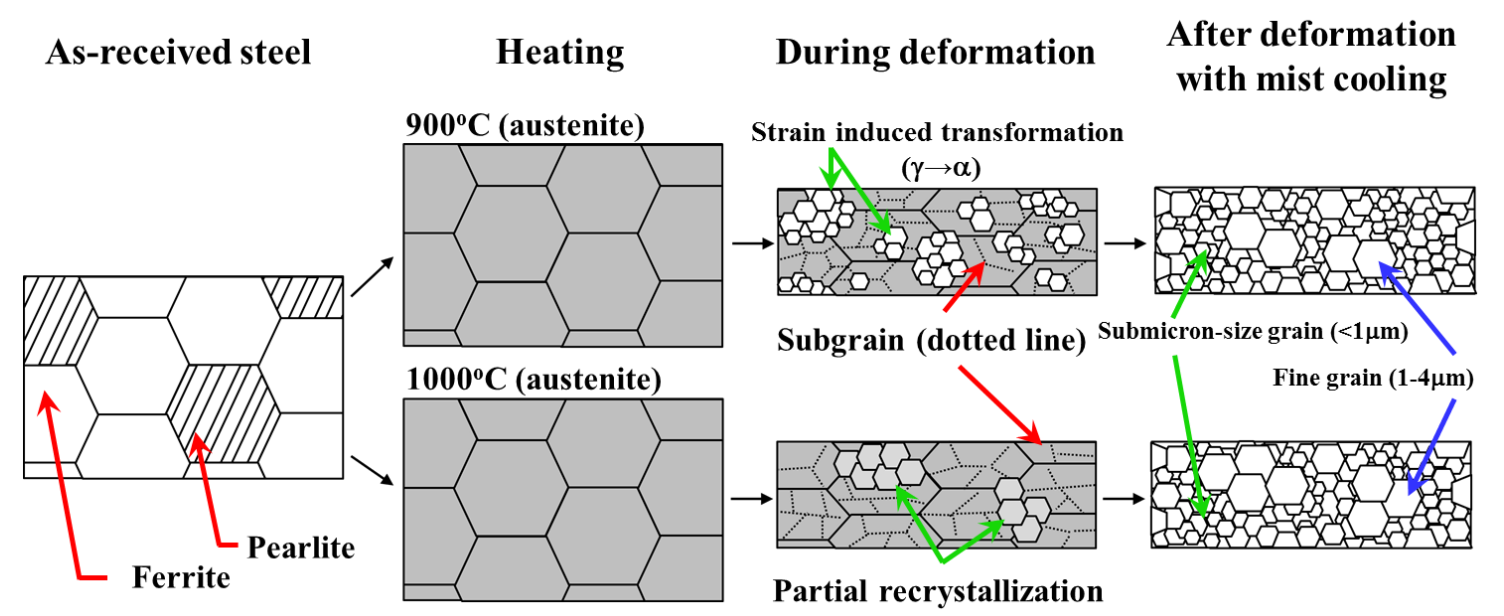

Fig. 12. Schematic illustration representing two types of the formation of the bimodal structure in $0.2 \%$ carbon steel during the processing. (the illustration of the specimen at a heating temperature of $900{ }^{\circ} \mathrm{C}$ is revised from our previous illustration of the specimen at a deformation temperature of $850{ }^{\circ} \mathrm{C}$ after the PSC test [42]). 


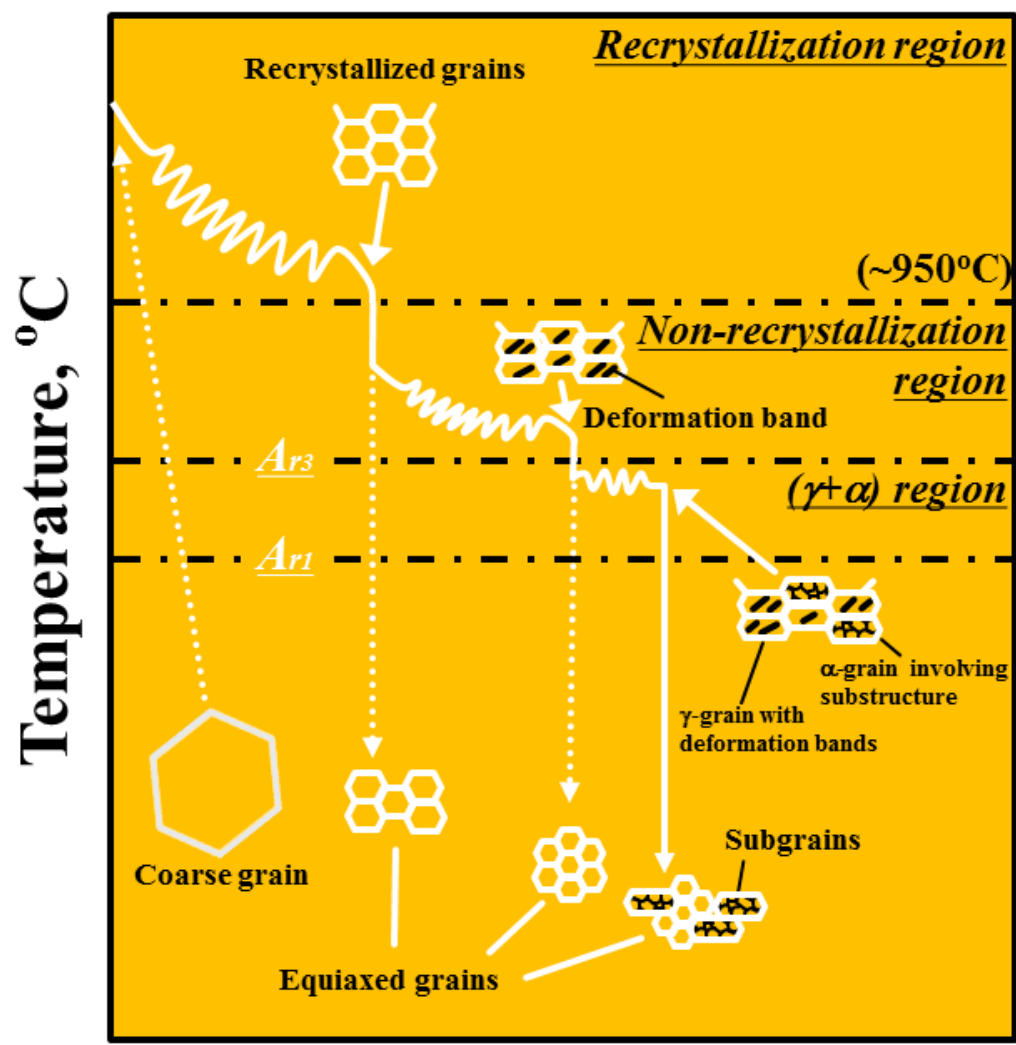

Strain, $\varepsilon$

Fig. 13. Schematic illustration of three stages of controlled rolling process and change in microstructure with deformation in each stage. [64] 